\title{
Gaps in the Newborn Screening Process: Using Maple Syrup Urine Disease as a Case
}

\author{
Mary Ann R. Abacan,, ${ }^{1,2}$ Sylvia C. Estrada, ${ }^{1,2,3}$ Leniza G. de Castro-Hamoy ${ }^{1,2}$ and Mary Anne D. Chiong ${ }^{1,2}$ \\ ${ }^{1}$ Division of Clinical Genetics, Department of Pediatrics, College of Medicine and Philippine General Hospital, University of the Philippines Manila \\ ${ }^{2}$ Institute of Human Genetics, National Institutes of Health, University of the Philippines Manila \\ ${ }^{3}$ Division of Endocrinology, Department of Pediatrics, College of Medicine and Philippine General Hospital, University of the Philippines Manila
}

\begin{abstract}
Saving babies from mental retardation and death is the aim of the newborn screening program. A complex process of sample collection, processing and feedback is undertaken before reaching this goal. As with other systems, the newborn screening program is not perfect and periodic review is needed to continually improve services. Using maple syrup urine disease (which is the most common inborn error of metabolism detected through newborn screening) as an index case, this paper aims to present the gaps in diagnosis and management by citing cases and providing a commentary.
\end{abstract}

Key Words: maple syrup urine disease, newborn screening, MSUD, NBS

\section{INTRODUCTION}

Maple syrup urine disease (MSUD) is an inborn error of metabolism caused by the deficiency or absence of the enzyme branched chain keto-acid dehydrogenase which results in an accumulation of the branched chain amino acids leucine, valine and isoleucine. ${ }^{1}$ Among the three amino acids, leucine is considered the most toxic. The name is derived from the sweet-smelling urine of patients afflicted with this disorder. Neonates with this condition are normal at birth but eventually present with poor suck, lethargy and seizures. Without proper treatment, patients succumb to coma and may die. ${ }^{2}$ Patients who survive the initial crisis may have developmental delay and neurologic sequelae. Favorable prognostic factors include an early age of diagnosis, a mild degree of illness during diagnosis, controlled leucine levels when well and during sick days, and access to acute medical care. ${ }^{3}$ The reported prevalence of MSUD in our country is 1 in 73,000 live births since its inclusion in the newborn screening program. ${ }^{4}$ The Metabolic Registry at the Institute of Human Genetics currently lists 195 patients diagnosed since $1990 . .^{5}$

The Philippine Newborn Screening Program was

Paper presented at the Newborn Screening Conference, October 3, 2017, Philippine International Convention Center.

Corresponding author: Mary Ann R. Abacan, MD

Division of Clinical Genetics

Department of Pediatrics

Philippine General Hospital

University of the Philippines Manila

Taft Avenue, Manila 1000, Philippines

Email:mrabacan@up.edu.ph formalized in 1996 and was integrated into the public health system in 2004. ${ }^{6}$ As of December 2017, there have been a total of almost 11 million newborns screened. Of these newborns, 7 million babies were screened for MSUD determined from the program in $2012 .{ }^{4}$ Currently, the newborn screening program screens for 28 disorders including amino acidurias, organic acidurias, fatty acid oxidation defects, urea cycle disorders, biotin-responsive disorders, endocrinologic disorders, hematologic disorders 


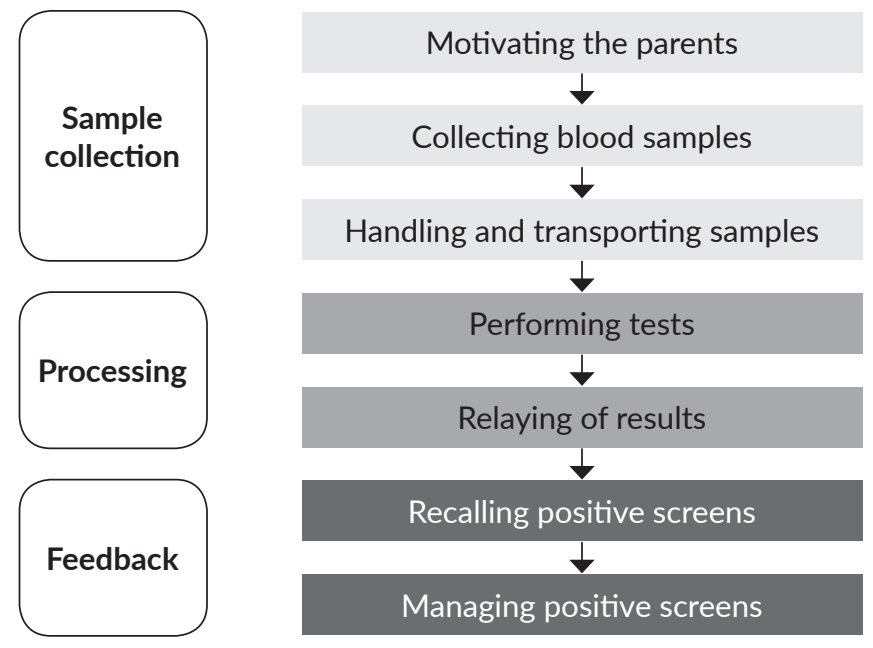

Figure 1. Newborn Screening Flow of Operation Process.

and cystic fibrosis. On average, the Newborn Screening Center of the National Institutes of Health (which is one of five NSC laboratories in the country), receives 1,600 samples per day which can go as high as 2,400 during the peak season. The overall recall rate for 2017 was $100 \%$ but the return rate (defined as number of patients who returned to the facility to repeat test or confirmatory test) was $82 \%$ (Dr Ana Lea Elizaga, Head of the Newborn Screening Center-National Institutes of Health, personal communication, 26 July 2018).

The flow of operation follows that of other newborn screening programs and are divided into three main parts: sample collection, processing and feedback. Sample collection includes motivation of parents, collecting of blood samples and the handling and transport of samples. Processing is the performing of the test and relaying the results. Finally, feedback is recalling positive screens and managing them accordingly. ${ }^{7}$ (Figure 1 )

In our country's ideal set-up, prior to delivery of the baby, the parents are made aware of newborn care and newborn screening. At the $24^{\text {th }}$ hour of life $^{8}$, a sample is taken via heel prick and by the following day, the hospital or newborn screening facility send the sample to the newborn screening laboratory for processing. By the $3^{\text {rd }}$ day of life, the dried blood spot has been processed and an elevated metabolite will warrant immediate recall and referral to the metabolic team. At the $4^{\text {th }}-5^{\text {th }}$ day of life, the newborn will have been seen and managed accordingly to avoid developing the signs and symptoms. However, no system is perfect and there are points for improvement as illustrated in the following vignettes based on our experiences from the past 5 years since the inclusion of MSUD in the newborn screening panel.

\section{CASE VIGNETTES AND COMMENTS}

\section{Case 1 - Lack of Awareness on NBS}

Baby Girl A is a 3-day-old child who was brought to the clinic for well-baby check-up. The pregnancy and the neonatal course was unremarkable. During routine history taking, it was noted that newborn screening was not done prior to discharge. The parents were unaware of this test and upon explanation of the healthcare provider, they consented to having a heel prick done for sample collection. This child had elevated levels of leucine and diagnosed with MSUD.

\section{Comment}

Being a program of the Department of Health, it has been recommended that prior to receiving $\mathrm{DOH}$ accreditation, health care facilities should be equipped to offer NBS. The cost of NBS remains to be an "out of pocket" expense because health insurance coverage is not 100\%. The Philippine insurance system has been making a move for point of care enrolment for Filipinos who do not have coverage. This process is on-going and may take some time before full coverage can be given to all Filipinos. In the meantime, the current situation is some babies are not offered newborn screening prior to discharge from health care facilities after birth.

Knowing about NBS may improve the chances of every newborn to have this test done. There are no local studies about the awareness of mothers or parents regarding NBS. Hasegawa et al. ${ }^{9}$ did a focus group discussion on parents and most participants did not recall having received any information on NBS. A similar study by Detmar et al. ${ }^{10}$ revealed that parents did not feel well-informed about newborn screening. In the US, Kumar et al. ${ }^{11}$ noted that $55 \%$ of parent and non-parent adults are not well aware of the existing NBS program. Awareness of newborn screening and its benefits should be part of the prenatal visit. Obstetricians and nurses are in the best position to discuss this with pregnant mothers. Once these mothers deliver, the importance of NBS remains in their consciousness and they can express their desire to have NBS done on their babies. Reinforcing the value of newborn screening can be done by the attending pediatrician or neonatologist once the babies are delivered. Providing information and answering any queries that parents may have regarding the test aids in the favorable response of parents to newborn screening.

\section{Case 2 - Late Sample Collection}

Baby Girl B was born at a lying-in clinic. The pregnancy was unremarkable and at birth she had good activity, cry and suck. She was discharged after 24 hours. Newborn screening was recommended but the parents opted to have it done after discharge. On the $3^{\text {rd }}$ day of life, she had fair suck and increased sleeping time but consult was done on the $4^{\text {th }}$ day of life. A newborn screening sample was sent and the patient had increased leucine. She was successfully recalled on the $6^{\text {th }}$ day of life. She was symptomatic and required dialysis to expedite the removal of toxins in her body. This resulted in a prolonged hospital stay due to nosocomial infection. She was discharged after three weeks and is on regular follow-up. 


\section{Comment}

Baby Girl B would have benefitted from newborn screening had her parents opted to have it done prior to discharge. Despite the recommendation to collect samples by the $24^{\text {th }}$ hour of life, De Castro-Hamoy et al. ${ }^{12}$ notes that newborn screening collection happens between the $1^{\text {st }}-11^{\text {th }}$ day of life with a mean of 4 days. The three-day delay is detrimental because patients begin to present with signs and symptoms. Early intervention is key to prevent complications. Developmental outcome is poor for those diagnosed at 7 days $^{3}$ due to leucine intoxication of the brain. For patients who are recalled at an older age group, the possibility of invasive means of toxin removal in the form of peritoneal dialysis (PD) increase considerably. This is due to the need for the immediate elimination of leucine from the body. The prolonged exposure of the brain to high leucine levels contribute to cerebral edema which contributes to the poor neurodevelopmental outcome. While PD may be life-saving, complications from the surgery can lead to prolonged hospital stay which in turn subjects the infant to a higher probability of acquiring a nosocomial infection. The timely collection of samples leads to timely intervention preventing complications.

\section{Case 3 - Batching of Samples}

Baby Boy C had an unremarkable neonatal course and was sent home after 24 hours. Prior to discharge, a newborn screening sample had been collected. He was recalled on the $5^{\text {th }}$ day of life due to increased leucine levels. He was admitted at a tertiary government hospital on the $7^{\text {th }}$ day of life now presenting with lethargy, poor suck and sweet smelling urine. He required dialysis. Upon investigation, it was noted that the hospital where the sample was collected practiced "batching" or waiting for samples to increase in size before sending them to the laboratory as a means of cutting costs of shipping.

Unfortunately, Baby $\mathrm{C}$ developed an abscess on the site of the Tenckhoff catheter insertion which led to a prolonged hospital stay. He was discharged after four weeks.

\section{Comment}

A practice known as "batching" is when hospitals wait to send larger groups of samples together which can save on shipping charges. ${ }^{13}$ Geographically, because our country is made up of thousands of islands, sending of samples to one of the five newborn screening centers can be challenging. Small hospitals opt to wait until a certain number of samples are reached before sending them to the lab.

The metabolic team who receives the patients in hospital alert the assigned newborn screening center who in turn calls the attention of the newborn screening facility. Newborn screening facilities are reminded constantly to avoid batching samples as these can cause delays in the detection of positive cases.

\section{Case 4 - Long Weekends and Holidays}

Baby Girl D was born in a hospital and had an unremarkable neonatal course. A newborn screening sample was collected on the $24^{\text {th }}$ hour of life and sent to the laboratory. The card reached the lab on a Friday afternoon. Processing for newborn screening cards are done in the morning and it is custom that cards received on a Friday afternoon are included in Monday's batch for processing. However, that weekend was a long weekend. Labor day holiday fell on a Monday. Baby Girl D's card was included in the Tuesday batch for processing. She was recalled on the $7^{\text {th }}$ day of life for increased leucine levels. Fortunately, she had a mild disorder and did not require admission to hospital. Dietary management was instituted and she remains on regular follow-up.

\section{Comment}

Newborn screening centers in the Philippines are not open 24 hours a day and 7 days a week. It is not uncommon to have 3-4 long weekends a year with holidays falling on Fridays or Mondays. When samples are received during the holidays they are typically not processed on the same day and there can be delays. This concern is not unique to our country. In the US, half the laboratories in the country are closed on weekends and holidays. ${ }^{13}$ These translate to delayed results which can spell more harm for children.

As a move to address this issue, the Newborn Screening Reference Center issued a memo stating that the laboratory should not be closed for more than two consecutive days. ${ }^{14}$ This ensures that timely and uninterrupted services are made available to the public.

\section{Case 5 - Wrong Information on NBS Cards}

Baby Boy $\mathrm{E}$ was born in a hospital and newborn screening was done on the $48^{\text {th }}$ hour of life. He was discharged well and did not have any signs and symptoms. On the $5^{\text {th }}$ day of life, he required recall due to elevated leucine levels but the recall team was unsuccessful. The contact number written on the card could not be reached. The help of the local government unit (LGU) was sought after 24 hours of unsuccessful recall. The LGU proceeded to go to the address written on the card only to be told that the patient no longer lived there. Through the help of barangay health workers (BHW), the family was found living under a bridge in the Manila area. The baby was brought to a tertiary government hospital and dietary management was instituted. He did not require dialysis. However, a bigger challenge was that the mother who is the primary caregiver was illiterate. The metabolic team devised a special system that would be easy for her to follow in feeding her baby. The LGU also assigned a roster of BHWs to visit the family daily and provide assistance in caring for the baby. 


\section{Comment}

Accurate information in the newborn screening cards is central to immediate recall. The follow-up nurses rely on the data written in the card as a means to contact parents should the need arise. To address this, proper education for parents to reiterate the importance of newborn screening and how the process works should be done at the point of collection. Health care personnel assigned to collect samples should likewise be vigilant and ensure that prior to collection, they have verified the information with the parents.

This case is a good example of how despite the less than ideal sample collection timing of the patient, a good recall system can be beneficial. It is custom that when the newborn screening centers cannot recall patients urgently, the local government unit is tapped to aid in the search of the patient. The network of the LGU far more exceeds the reach of the NSC. Because LGUs are given periodic lectures on newborn screening, the importance of immediate action is embedded in their consciousness.

In addition, for this case, the metabolic team used pictures to depict the time of feeding which the mother can compare with her clock's face. Color coded containers with pre-measured scoops of regular milk formula and medical food are prepared for her daily. Prior to discharge from the hospital, several demo-return demos were done to ensure the mother's understanding of the diet plan. In coordination with the LGU, a BHW was assigned to visit the family daily to aid in the preparation of the child's milk and to check on how the mother is coping.

The management of MSUD is heavily anchored on dietary modification which entails counting natural protein and caloric intake. In the beginning, parents can be overwhelmed by feeding schedules and the balance of supplying adequate protein and providing medical food. Any excess or lack in the dietary regimen can be detrimental to the child. Parents will often need continued psychosocial support and positive reinforcement while dealing with a child with a chronic illness.

\section{Case 6 - Refusal of Parents}

Baby Boy $\mathrm{F}$ had an unremarkable neonatal course. The newborn screening sample taken on the $24^{\text {th }}$ hour of life showed a mild elevation of leucine. The family was successfully contacted and was advised to have the levels repeated. Despite speaking with the parents and explaining the urgency of the situation, the family remained steadfast in their decision not to have the sample repeated. They opted to sign a refusal form. This baby was lost to follow-up and his current clinical status is unknown.

\section{Comment}

The Newborn Screening Law ${ }^{15}$ or Republic Act 9288 aims to provide an opportunity for every newborn for early identification of conditions that can cause mental retardation or death. NBS is not mandatory in our country. Parents are given the option to sign a refusal form ${ }^{16}$ which states that despite the information given regarding NBS (procedure, benefit and availability) and the catastrophic consequences of undiagnosed metabolic conditions, parents still do not want to avail the test. They are also asked to state their reasons for refusal in writing.

Reasons for refusal can be varied and in keeping with allowing parents to exercise their autonomy, once the form is signed, the health care provider will respect their decision. Providing the proper information to parents is key in making them understand the benefits of newborn screening. Our limitation as health care providers is parents are expected to act in the best interest of their children, their decisions are respected.

\section{Case 7 - Caregiver Fatigue}

Baby Girl G is the second child of a non-consanguineous couple of Filipino descent born in one of the islands in Region IV-B. Their older child was diagnosed with MSUD and had died at 1 year of age. Baby Girl G's newborn screening sample was collected on the $7^{\text {th }}$ day of life. The increased leucine levels prompted recall and subsequent admission to a tertiary government hospital. She underwent dialysis and was discharged after two weeks. However, she was unable to come for her follow-up consult despite assistance from the LGU. Her parents cited financial difficulties and logistical reasons for not consulting. The team learned that Baby Girl G died after a few weeks.

\section{Comment}

This case emphasizes that while healthcare providers share in the care for patients, a bulk of the responsibility lies in the shoulders of the family. Psychosocial support and continuous education with every follow-up should be given to caregivers. As with other chronic illness, it is important to also check on the well-being of the primary caregiver as they can be subject to fatigue. ${ }^{17}$ To maximize the management of the child, a strong partnership is needed between the medical team and the family. In the real world, this can be very challenging especially when there are factors unbeknownst to the healthcare providers that can affect the effective management.

In summary, the table below highlights the different gaps identified and the opportunities for improvement (Table 1).

\section{CONCLUSIONS}

MSUD is one of the common inborn errors of metabolism present in the Philippine population. The key is early detection for early recall and institution of management. Saving babies from death and mental retardation does not end with a positive screen, it is merely the beginning. To ensure survival, the management of MSUD, much like other IEMs requires a multidisciplinary approach. It is through the combined efforts of the caregivers, the healthcare providers 
Table 1. Summary of the Gaps in the Newborn Screening Process and Opportunities for Improvement

\begin{tabular}{cll} 
Case & \multicolumn{1}{c}{ Gap Identified } & \\
\hline 1 & $\begin{array}{l}\text { Lack of Awareness on } \\
\text { Newborn Screening }\end{array}$ & Improve parent's knowledge/awareness about NBS during the pre-natal period \\
\hline 2 & Late Sample Collection & Improve education of healthcare providers and parents regarding the importance of timely sample collection \\
\hline 3 & Batching of Samples & $\begin{array}{l}\text { Improve the education of healthcare providers and newborn screening facilities regarding the importance of } \\
\text { timely sending of NBS cards for processing }\end{array}$ \\
\hline 4 & $\begin{array}{l}\text { Long Weekends and } \\
\text { Holidays }\end{array}$ & $\begin{array}{l}\text { Consider the processing of NBS cards over the weekend to improve services and timely feedback for patients } \\
\text { who screen positive }\end{array}$ \\
\hline 5 & $\begin{array}{l}\text { Wrong Information on } \\
\text { NBS Cards }\end{array}$ & $\begin{array}{l}\text { Improve the parent's and health care provider's knowledge on the importance of giving correct information } \\
\text { for easier recall should a patients screen positive }\end{array}$ \\
\hline 7 & Refusal of Parents & Improve parent's education regarding the importance of NBS and the missed opportunity should they dissent \\
\hline
\end{tabular}

who collect the samples, the couriers who deliver the cards to the laboratory, the technicians who process the cards, the follow-up team who recalls the positive screens, the medical team managing the patient and the support system from government agencies that allow children with MSUD to survive. The newborn screening system in the Philippines is not perfect and there is much room for improvement. The first step is to recognize the gaps so that processes can be put into place to enhance the system.

\section{Statement of Authorship}

All authors have approved the final version submitted.

\section{Author Disclosure}

All authors declared no conflicts of interest.

\section{Funding Source}

None.

\section{REFERENCES}

1. Dancis J, Hutzler J, Levitz M. Metabolism of the white blood cells in maple-syrup-urine-disease. Biochim Biophys Acta. 1960 Sep; 43: 342-3.

2. Frazier DM, Allgeier C, Homer C, Marriage BJ, Ogata B, Rohr F, et al. Nutrition management guideline for maple syrup urine disease: an evidence and consensus-based approach. Mol Gen Metab. 2014 Jul; 112(3):210-7.

3. Morton DH, Strauss KA, Robinson DL, Puffenberger EG, Kelley RI. Diagnosis and treatment of maple syrup urine disease: a study of 36 patients. Pediatrics. 2002 Jun; 109(6):999-1008.

4. Newborn Screening Reference Center, Newborn statistics 2017 [Internet].[cited2018Jul20].Available from:https://newbornscreening. $\mathrm{ph} /$ index.php?option=com_content\&view=article\&id=83:nbs-statistic s\&catid $=32$ : statistics\&Itemid $=57$
5. Metabolic Registry, Institute of Human Genetics, 2017.

6. Padilla CD. Enhancing case detection of selected inherited disorders through expanded newborn screening in the Philippines. Acta Med Philipp. 2012; 46(4):24-9.

7. Newborn Screening Reference Center, Facilitators' Guidebook [Internet]. [cited 2018 Feb 19]. Available from: https:// newbornscreening.ph/index.php?option=com_content\&view=section \&layout=blog\&id=5\&Itemid=57

8. Newborn Screening Reference Center Memo 2014-015, 21 May 2014.

9. Hasegawa LE, Fergus KA, Ojeda N, Au SM. Parental attitudes toward ethical and social issues surrounding the expansion of newborn screening using new technologies. Public Health Genomics. 2011; 14(4-5):298-306.

10. Detmar S, Hosli E, Dijkstra N, Nijsingh N, Rijnders M, Verweij M. Information and informed consent for neonatal screening: opinions and preferences of parents. Birth. 2007 Sep; 34(3):238-44.

11. Kumar P, Iyengar H, Kumar P. Public Awareness of and Attitudes toward Newborn Screening. Remedy Open Access. 2017; 2:1040

12. De Castro-Hamoy LG, Chiong MD, Estrada SC, Cordero CP. Challenges in the management of patients with maple syrup urine disease diagnosed by newborn screening in a developing country. J Community Genet. 2017 Jan; 8(1):9-15.

13. Gabler E. How newborn testing should work [Internet]. Journal Sentinel. Nov. 16, 2013 [cited 2018 Feb 19]. Available from: http:// archive.jsonline.com/watchdog/watchdogreports/Deadly-DelaysHow-the-newborn-screening-process-should-work-231912731.html

14. Newborn Screening Reference Center Memo 2017-037, 13 December 2017.

15. Republic Act 9288. An act promulgating a comprehensive policy and a national system for ensuring newborn screening [Internet]. [cited 2018 Feb 19]. Available from: https://newbornscreening.ph/ index.php?option=com_content\&view=section \&layout=blog\&id= 5\&Itemid $=57$

16. Newborn Screening Reference Center Memo 2011-012,17 May 2017.

17. Zeltner NA, Landolt MA, Baumgartner MR, Lageder S, Quitmann $\mathrm{J}$, Sommer R, et al. Living with intoxication-type inborn errors of metabolism: a qualitative analysis of interviews with paediatric patients and their parents. JIMD Rep. 2017; 31:1-9 